\title{
CÁLCULO E PREPARO DE SOLUÇÕES TAMPÃO: GUIA COMPLETO USANDO O SOFTWARE PEAKMASTER ${ }^{\circledR}$
}

\author{
Olívia Brito de Oliveira Moreira ${ }^{\mathrm{a}}$, Larissa dos Anjos Castro $^{\mathrm{a}}$ e Marcone Augusto Leal de Oliveira ${ }^{\mathrm{a}, *, \odot}$ \\ ${ }^{a}$ Departamento de Química, Instituto de Ciências Exatas, Universidade Federal de Juiz de Fora. 36036-900, Juiz de Fora - MG, Brasil
}

Recebido em 21/10/2020; aceito em 08/12/2020; publicado na web em 20/01/2021

\begin{abstract}
CALCULATION AND PREPARATION OF BUFFER SOLUTIONS: COMPLETE GUIDE USING THE SOFTWARE PEAKMASTER $^{\circledR}$. Buffers are a widely used resource to keep solutions from abruptly change their $\mathrm{pH}$ when amounts of acids or bases are added or when dilution occurs. Considering this, buffer is a topic addressed in several university majors and due its relevance should be well known by students and by all professionals who eventually need to prepared a buffer. Mistakes during the procedure might bring unwanted effects depending on the purpose of the buffer. Even though the theory behind buffers is extensively covered in textbooks, the calculations required can sometimes be interpreted as difficult. Therefore, the aim of this work is to disseminate a tool to assist on these calculations. We provide a practical guide on how to prepare buffers of the user's choice with or without ionic strength adjustment. Exploring the free software PeakMaster®, the user can calculate $\mathrm{pH}$, ionic strength, buffer capacity and predict the precise concentration of each component involved to the proper preparation of the most common and several others buffer solutions. In addition, we hope this paper can be helpful for anyone who is interested in acquire deeper knowledge about buffers.
\end{abstract}

Keywords: buffer; ionic strength; buffer capacity; PeakMaster ${ }^{\circledR}$.

\section{INTRODUÇÃO}

Por definição, tampões são soluções aquosas cujo potencial hidrogeniônico $(\mathrm{pH})$ tende a permanecer constante quando submetidos à diluição ou à adição de pequenas quantidades de ácidos ou bases, fortes ou fracos. São caracterizados por serem soluções preparadas a partir da mistura de um ácido fraco e sua base conjugada ou de uma base fraca e seu ácido conjugado. ${ }^{1-4}$ As aplicações das soluções tampão são fundamentais e abrangentes em diversas áreas do conhecimento como, por exemplo, farmacêutica, alimentícia, biológica, química, médica, clínica e ambiental. ${ }^{1,4}$

Um bom exemplo da atuação de soluções tampão são os processos bioquímicos que ocorrem nos organismos. Todas as reações envolvidas são dependentes do $\mathrm{pH}$, ou seja, a ausência do tamponamento do meio pode provocar uma grande alteração do sistema. Nesse sentido, o controle do $\mathrm{pH}$ se torna muitas vezes imprescindível e, por isso, os tecidos de plantas e o sangue são excelentes exemplos a serem considerados. ${ }^{1,5}$

Diversos seguimentos da indústria também fazem uso de sistemas tampões em seus processos. Na produção de fármacos, por exemplo, o controle do pH é uma das estratégias para que a formulação seja produzida no doseamento desejado. Já na indústria alimentícia, é comum o uso de tampões com a função de agente conservante direcionado a evitar a deterioração dos produtos por bactérias. ${ }^{2,5,6}$

Para alguns propósitos, também é considerada a força iônica da solução, que apesar de sua importância, por muitas vezes é negligenciada. ${ }^{7-9}$ A força iônica é a medida da concentração total de íons em solução e é uma grandeza que influencia diretamente alguns fenômenos químicos..$^{4,10}$ Por exemplo, a força iônica pode influenciar o $\mathrm{pH}$ do solo, ${ }^{11}$ os processos de adsorção de biomoléculas como as proteínas ${ }^{12-16}$ e solubilidade de compostos orgânicos. ${ }^{17,18}$ Consequentemente, o controle da força iônica entre estes e outros sistemas é essencial. ${ }^{19}$

Devido à relevância, o preparo de soluções tampão é um assunto inerente à ementa de cursos universitários que envolvem conhecimentos de química, farmácia, bioquímica, biologia e

*e-mail: marcone.oliveira@ufjf.edu.br biomedicina. De acordo com Caldwell et al., é desejável que os egressos destes cursos adquiram conhecimento e experiência necessários sobre o assunto, bem como, se tornem proficientes no preparo de soluções tampão..$^{20,21}$

No entanto, em alguns casos, os cálculos referentes ao preparo de soluções tampão, com ou sem ajuste de força iônica, podem ser considerados complicados, principalmente em sistemas complexos e que envolvem ácidos polipróticos e sais com ânions polivalentes, por exemplo.

Dentro desse contexto, acredita-se que este artigo poderá ser de grande utilidade para docentes, discentes de graduação e pós graduandos, bem como para qualquer profissional que necessite preparar uma solução tampão para determinado fim. Adicionalmente, poderá servir também como um material complementar, de consulta ou de estudos para aqueles interessados em adquirir maiores informações sobre o tema. Nesse sentido, os autores deste trabalho têm como objetivo principal divulgar o software PeakMaster ${ }^{\circledR}$, o qual foi construído com ferramentas simples, rápidas, eficazes e eficientes, como um mecanismo opcional para o cálculo do preparo de soluções tampão. O PeakMaster ${ }^{\circledR}$ é um software gratuito desenvolvido pelo grupo de pesquisa da Faculdade de Ciências da Charles University, liderado pelo Prof. Dr. Bohuslav Gaš. ${ }^{22,23}$ O programa computacional é voltado, a priori, para simulação de condições experimentais imanentes a técnica de eletroforese capilar. Porém, entre os comandos disponíveis no software, existe a possibilidade de realizar cálculos envolvendo $\mathrm{pH}$, força iônica e capacidade tamponante de soluções tampão a partir de um portifólio amplo de combinações de reagentes.

\section{EXPERIMENTAL}

\section{Software}

O PeakMaster ${ }^{\circledR}$ é um software disponibilizado gratuitamente nas versões 5.3 e 5.4 pela plataforma https://web.natur.cuni.cz/gas/ peakmaster.html. Caso haja interesse no aprofundamento dos recursos do software, um guia também é disponibilizado gratuitamente na plataforma https://echmet.natur.cuni.cz/software/peakmaster. 
Neste trabalho, serão apresentados alguns recursos do PeakMaster $^{\circledR}$, relacionando as informações necessárias para o preparo de soluções tampão com ou sem ajuste de força iônica. Com o auxílio do software, o usuário poderá (a) calcular o $\mathrm{pH}$ de soluções com concentrações conhecidas; (b) determinar as concentrações dos reagentes necessários para o preparo de uma solução tampão; (c) obter valor da capacidade tamponante; (d) calcular a força iônica de qualquer solução de concentração conhecida.

Aliado ao PeakMaster ${ }^{\circledR}$, alguns cálculos simples também serão explicitados na intenção de fornecer um protocolo aos interessados em preparar uma solução tampão.

\section{FUNDAMENTOS TEÓRICOS}

\section{Solução tampão}

A solução tampão é um recurso utilizado com o objetivo de manter o pH de um sistema de interesse constante, dentro de um intervalo de variação restrito. Tampões consistem da mistura de um ácido fraco (doador de prótons) e sua base conjugada (aceptor de prótons), ou da mistura de uma base fraca e seu ácido conjugado segundo definição de ácido-base de BrØnsted-Lowry. Sob outra perspectiva, considerando o conceito de ácido e base mais abrangente definido por Lewis, o tampão pode ser constituido pela mistura de um ácido fraco (receptor de par de elétrons) e sua base conjugada (doadora de par de elétrons), ou da mistura de uma base fraca e seu ácido conjugado. ${ }^{2-4}$

Ao adicionarmos um ácido a um sistema tamponado, este será consumido pela base conjugada que compõe o tampão. Analogamente, ao ser adicionada uma base forte ao sistema, esta reagirá com a espécie ácida do tampão. Mesmo com essas perturbações provocadas ao sistema, o equilíbrio químico é deslocado seguindo o princípio de Le Châtelier ("A aplicação de uma perturbação em um sistema químico em equilíbrio resultará em uma mudança na posição do equilíbrio no sentido de minimizar o efeito da perturbação") ${ }^{3}$ e, dessa forma, não há alterações significativas no valor do $\mathrm{pH}$ medido da solução. ${ }^{4}$

Por exemplo, um tampão muito utilizado é o sistema ácido acético/acetato $\left(\mathrm{CH}_{3} \mathrm{COOH} / \mathrm{CH}_{3} \mathrm{COO}^{-}\right)$, descrito conforme a expressão de equilíbrio 1:1,24

$$
\mathrm{CH}_{3} \mathrm{COOH}(\mathrm{aq})+\mathrm{H}_{2} \mathrm{O}(\mathrm{l}) \rightleftharpoons \mathrm{H}_{3} \mathrm{O}^{+}(\mathrm{aq})+\mathrm{CH}_{3} \mathrm{COO}^{-}(\mathrm{aq})
$$

O equilíbrio é representado por uma constante de equilíbrio ácida (Ka), ou seja, a constante de ionização, descrita segundo a equação $2:^{24}$

$$
\mathrm{Ka}=\frac{\left[\mathrm{H}_{3} \mathrm{O}^{+}\right]\left[\mathrm{CH}_{3} \mathrm{COO}^{-}\right]}{\left[\mathrm{CH}_{3} \mathrm{COOH}\right]}=1,75 \times 10^{-5}
$$

Ao analisar a equação 2, pode-se observar que as concentrações do ácido acético e a de sua base conjugada (acetato) podem ser relacionadas à concentração de $\mathrm{H}_{3} \mathrm{O}^{+}$. Nesse sentido, através do rearranjo algébrico entre as concentrações das espécies, pode-se descrever um modelo que possibilite o cálculo teórico preciso das concentrações dos reagentes necessários para o preparo da solução tampão. Nessa lógica, a equação Henderson-Hasselbalch, a qual foi construída para esse fim, nada mais é do que um rearranjo da constante de equilíbrio em escala logarítmica. A equação de HendersonHasselbalch é descrita conforme a expressão $3::^{2-4,24}$

$$
\mathrm{pH}=\mathrm{pKa}+\log \frac{\left[\mathrm{A}^{-}\right]}{[\mathrm{HA}]}
$$

em que pKa é o logaritimo da constante de equilíbrio Ka, [A-] é a concentração da base conjugada e [HA] a concentração do ácido. A dedução da equação de Henderson-Hasselbalch para pH e pOH está detalhada no material suplementar.

Para o sistema tampão $\left(\mathrm{CH}_{3} \mathrm{COOH} / \mathrm{CH}_{3} \mathrm{COO}^{-}\right)$, o preparo de uma solução utilizando, por exemplo, $50 \mathrm{mmol} \mathrm{L}^{-1}$ de uma solução de ácido acético e $50 \mathrm{mmol} \mathrm{L}^{-1}$ de uma solução de acetato de sódio (ou qualquer contraíon compatível), resultará em uma solução tampão com concentração total de $100 \mathrm{mmol} \mathrm{L}^{-1} \mathrm{e} \mathrm{pH}$ muito próximo de 4,74. De acordo com os cálculos das expressões 4, 5 e 6 :

$$
\begin{aligned}
& \mathrm{pKa}=-\log \mathrm{Ka}=-\log 1,75 \times 10^{-5}=4,74 \\
& \mathrm{pH}=4,74+\log \frac{50 \mathrm{mmol} \mathrm{L}^{-1}}{50 \mathrm{mmol} \mathrm{L}^{-1}} \Rightarrow \mathrm{pH}=4,74 \\
& \mathrm{C}_{\text {Total }}=\mathrm{C}_{\text {ácido }}+\mathrm{C}_{\text {base conjugada }}=50 \mathrm{mmol} \mathrm{L}^{-1}+50 \mathrm{mmol} \mathrm{L}^{-1} \\
&=100 \mathrm{mmol} \mathrm{L}^{-1}
\end{aligned}
$$

Pergunta-se, o preparo da solução tampão pode ser realizado apenas a partir desses reagentes? A resposta é: não necessariamente! Suponha que no laboratório esteja disponível apenas o ácido acético, ou seja, não há o binômio ácido acético e acetato de sódio. Isso não impede que o tampão seja preparado. Voltemos ao equilíbrio químico que representa o sistema tampão $\left(\mathrm{CH}_{3} \mathrm{COOH} / \mathrm{CH}_{3} \mathrm{COO}^{-}\right)$, que também pode ser escrito conforme a expressão de equilíbrio 7 :

$$
\mathrm{CH}_{3} \mathrm{COOH}(\mathrm{aq})+\mathrm{OH}^{-}(\mathrm{aq}) \rightleftharpoons \mathrm{CH}_{3} \mathrm{COO}^{-}(\mathrm{aq})+\mathrm{H}_{2} \mathrm{O}(\mathrm{l})
$$

Para o preparo do mesmo tampão com concentração total de $100 \mathrm{mmol} \mathrm{L}^{-1}$, podemos a partir de um volume de ácido acético correspondente ao preparo de uma solução $100 \mathrm{mmol} \mathrm{L}^{-1}$, adicionar uma massa de uma base forte, como o hidróxido de sódio por exemplo, que corresponda a uma solução com concentração total de $50 \mathrm{mmol} \mathrm{L}^{-1}$. A base adicionada reagirá de maneira equimolar com a metade da concentração do ácido acético e desta forma, o equilíbrio será deslocado em $50 \%$ no sentido da formação do acetato de sódio, resultando em um sistema tamponado.

Analogamente, pode-se adicionar um ácido forte, como o ácido clorídrico $(\mathrm{HCl})$, a uma massa de acetato de sódio necessária para o preparo de uma solução $100 \mathrm{mmol} \mathrm{L}^{-1} \mathrm{e}$, dessa forma, deslocar o equilíbrio no sentido de obter ácido acético e acetato de sódio em concentrações equivalentes, resultando em um sistema tamponado. Portanto, não é apenas a partir dos reagentes que compõem o equilíbrio correspondente ao tampão desejado que a solução pode ser preparada. Com cálculos precisos, é possivel controlar o sistema, ou seja, deslocar o equilíbrio no sentido de interesse a partir dos reagentes disponíveis no laboratório.

\section{Capacidade tamponante}

No exemplo apresentado, a priori, foi demonstrado o preparo de uma solução tampão com concentrações iguais de ácido e base conjugada. Nesse caso, o pH é igual ao pKa e a solução tampão apresenta máxima capacidade tamponante, a qual é a medida de quanto a solução resiste a adição de ácidos ou bases fortes. Na prática, o valor da capacidade tamponante indica a quantidade de ácido ou base que pode ser adicionada sem a solução perder a natureza tamponante. É definida conforme a equação 8:4,25

$$
\beta=\frac{\Delta \mathrm{C}_{\mathrm{a}}}{\Delta \mathrm{pH}}=\frac{\Delta \mathrm{C}_{\mathrm{b}}}{\Delta \mathrm{pH}}
$$

em que $\mathrm{C}_{\mathrm{a}}$ e $\mathrm{C}_{\mathrm{b}}$ são as concentrações molares de ácido e base necessários para produzir mudanças em uma unidade de $\mathrm{pH}$. Quanto maior for a capacidade tamponante, maior é a capacidade do tampão de resistir 
a adição de ácidos e/ou bases. ${ }^{4,25} \mathrm{~A}$ máxima capacidade tamponante é o ponto em que a solução tampão sofre menos influência da adição de ácidos e/ou bases. É importante ressaltar que a capacidade de uma solução se comportar como um tampão também depende de sua concentração total. Se um tampão for muito diluído, terá uma capacidade tamponante menor do que o mesmo volume de uma solução tampão mais concentrada. ${ }^{25} \mathrm{~A}$ capacidade da solução de se comportar como um tampão diminui à medida que a razão das concentrações das espécies reagentes envolvidas torna-se menor do que 1. Em geral, uma solução tampão é eficiente dentro do intervalo de $-1 \leq \mathrm{pKa} \leq+1$. $^{2-4,24,25}$

Vale ressaltar ainda que algumas soluções, apesar de apresentarem efeito tamponante, não são soluções tampão por definição! Primeiramente, precisamos lembrar que a medida de $\mathrm{pH}$ é realizada de maneira indireta através de um $\mathrm{pHmetro,} \mathrm{o} \mathrm{qual} \mathrm{pode} \mathrm{ser} \mathrm{construído}$ a partir do arranjo do eletrodo de membrana de vidro, sensível a atividade de íons $\mathrm{H}^{+}$em solução, com os eletrodos de referência interna e externa capazes de mediar processos redox. ${ }^{3}$ As informações compiladas do sistema eletroquímico, em conjunto com a aplicação do conceito e fundamentos da equação de Nernst, resulta na informação da medida do $\mathrm{pH}$. Logo, se adicionarmos certas quantidades de um ácido ou uma base forte a uma solução concentrada de hidróxido de sódio em pH igual a 13, por exemplo, a alteração no valor do $\mathrm{pH}$ do meio não será significativa.

O entendimento do fato é muito simples. Caso seja adicionado um ácido à solução, os cátions $\mathrm{H}^{+}$serão consumidos por ânions $\mathrm{OH}^{-}$ presentes na solução em concentrações muito altas. Em contrapartida, caso seja adicionado uma base à solução, o incremento de ânions $\mathrm{OH}^{-}$é muito menor do que quantidade dos ânions $\mathrm{OH}^{-}$já existente no sistema. Em ambos os casos, o valor nominal do $\mathrm{pH}$ registrado pelo pHmetro não sofrerá uma variação impactante.

Para não perder o foco da discussão, apenas é alertado a possível ocorrência dos erros ácidos ou alcalinos inerentes a medida de $\mathrm{pH}$ quando utilizado o eletrodo de membrana de vidro. Contudo, dentro da premissa da discussão aqui elencada, pode se concluir que, apesar de algumas soluções não se tratarem de um sistema tampão propriamente dito, é observado o efeito tamponante.

\section{Força iônica}

Em alguns casos, é importante o preparo de uma solução tamponada com a força iônica controlada. A força iônica é uma grandeza definida conforme a equação 9:2-4

$$
\mathrm{I}=\frac{1}{2}\left([\mathrm{~A}] \mathrm{Z}_{\mathrm{a}}^{2}+[\mathrm{B}] \mathrm{Z}_{\mathrm{b}}^{2}+\ldots+[\mathrm{N}] \mathrm{Z}_{\mathrm{n}}^{2}\right)
$$

em que [A], [B] e [N] são as concentrações das espécies iônicas e $Z_{a}$, $\mathrm{Z}_{\mathrm{b}}$ e $\mathrm{Z}_{\mathrm{n}}$ suas respectivas cargas.

Supondo que seja necessário o preparo de uma solução tampão $\left(\mathrm{CH}_{3} \mathrm{COOH} / \mathrm{CH}_{3} \mathrm{COO}^{-}\right)$com concentração total de $100 \mathrm{mmol} \mathrm{L}{ }^{-1}, \mathrm{pH}$ 4,74 e força iônica de $200 \mathrm{mmol} \mathrm{L}^{-1}$. Nesse caso, é preciso adicionar ao tampão uma certa quantidade de um sal solúvel. Por exemplo, pode-se utilizar um sal de um cátion monovalente $\left(\mathrm{M}^{+} \mathrm{A}^{-}\right)$, como o cloreto de potássio $(\mathrm{KCl})$. Para inferir sobre a quantidade necessária a ser adicionada, inicialmente precisamos calcular a força iônica apenas do tampão. Considerando que temos em solução acetato de sódio a $50 \mathrm{mmol} \mathrm{L}^{-1}$ e que a concentração de $\mathrm{H}_{3} \mathrm{O}^{+}$é muito menor do que a concentração das demais espécies $\left(1,75 \times 10^{-5} \mathrm{~mol} \mathrm{~L}^{-1} \leq 0,05 \mathrm{~mol} \mathrm{~L}^{-1}\right)$, portanto pode ser desconsiderada, a força iônica do sistema pode ser calculada a partir da equação correspondente supracitada, conforme apresentado na expressão 10:

$$
\mathrm{I}=\frac{1}{2}\left(\left[\mathrm{CH}_{3} \mathrm{COO}^{-}\right] \times(-1)^{2}+\left[\mathrm{Na}^{+}\right] \times(+1)^{2}\right)
$$

Aplicando-se os respectivos valores à expressão, de acordo com a expressão 11 temos:

$$
\mathrm{I}=\frac{1}{2}\left(50 \mathrm{mmol} \mathrm{L}^{-1} \times(-1)^{2}+50 \mathrm{mmol} \mathrm{L}^{-1} \times(+1)^{2}\right)
$$

A partir de uma subtração simples, pode-se calcular a concentração de um sal $\mathrm{M}^{+} \mathrm{A}^{-}$que deve ser adicionado para atingir a força iônica requerida, conforme a expressão 12:

$\mathrm{I}=\mathrm{I}_{\text {desejada }}-\mathrm{I}_{\text {atual }}=200 \mathrm{mmol} \mathrm{L}-1-50 \mathrm{mmol} \mathrm{L}^{-1}=150 \mathrm{mmol} \mathrm{L}^{-1}$

Logo, para atingir a força iônica necessária sem alterar a concentração do tampão, é preciso adicionar uma massa de

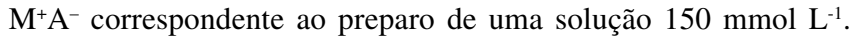
Recalculando a força iônica já considerando a adição de $\mathrm{M}^{+} \mathrm{A}^{-}$, de acordo com a expressão 13 , temos:

$\mathrm{I}=\frac{1}{2}\left(50 \times(-1)^{2}+50 \times(+1)^{2}+150 \times(-1)^{2}+150 \times(+1)^{2}\right)=200 \mathrm{mmol} \mathrm{L}^{-1}$

Se não fosse necessário manter fixa a concentração do tampão, ela poderia ser modificada através da alteração das concentrações dos reagentes até atingir a força iônica desejada, desde que fosse mantida a proporção entre ácido e base conjugada. Outro exemplo de ajuste de força iônica utilizando sais de cátions povilaventes é comentado no material suplementar.

\section{Cálculo de massa e/ou volume dos reagentes selecionados para o tampão}

Uma vez determinadas as concentrações, a etapa posterior envolve o cálculo das massas e dos volumes de reagentes a serem usados para o preparo da solução tampão. De modo geral, para concentrações em mol L'-1, de acordo com as equações 14,15 e 16 temos que: ${ }^{2,4}$

$$
\begin{gathered}
\mathrm{C}(\mathrm{M})=\frac{\mathrm{n}}{\mathrm{V}} \\
\mathrm{n}=\frac{\mathrm{m}}{\mathrm{MM}}
\end{gathered}
$$

Substituindo (14) em (15), temos: $C(M)=\frac{\mathrm{m}(\mathrm{g})}{\mathrm{MM}\left(\mathrm{g} \mathrm{mol}^{-1}\right) \times \mathrm{V}(\mathrm{L})}$

em que n é o número de mols do reagente, MM é a massa molar, $\mathrm{V}$ é o volume total da solução tampão a ser preparada e $m$ a massa do reagente a ser pesada.

Para reagentes em solução, a massa a ser calculada deve ser relacionada com a respectiva densidade, de modo a obter o volume a ser transferido, de acordo com a equação 17: 2,4

$$
\rho=\frac{\mathrm{m}}{\mathrm{V}}
$$

em que $\rho$ é a densidade da solução, m a massa e $\mathrm{V}$ o volume do reagente a ser transferido.

É importante considerar ainda o grau de pureza de cada reagente. Caso desconsiderado, a solução tampão não será preparada de acordo com a concentração adequada e, consequentemente, não será ajustado o pH desejado. Por exemplo, supondo que deve ser preparada uma solução a partir de um reagente com $75 \%$ de pureza e após a realização dos cálculos citados obteve-se um volume de $5 \mathrm{~mL}$. Esse volume será necessário para atingir a concentração desejada? Não! Logo, devemos considerar a pureza para corrigir o volume a ser usado, de acordo com a equação 18 : 


$$
\frac{\mathrm{V}_{\text {calculado }}}{\text { percentual de pureza }} \times 100 \therefore \frac{5 \mathrm{~mL}}{75} \times 100 \simeq 6,7 \mathrm{~mL}
$$

Uma vez que o reagente não apresenta $100 \%$ de pureza, para atingir a concentração necessária deve ser medido um volume maior do que o previamente calculado. Essa etapa de cálculos é de grande importância para o preparo inequívoco de soluções tampão ou procedimentos de qualquer natureza envolvendo questões estequiométricas.

\section{USANDO O PEAKMASTER ${ }^{\circledR}$}

Os cálculos envolvendo o preparo de soluções tampão por muitas vezes não são simples, sobretudo na previsão das concentrações a serem usadas para atingir o $\mathrm{pH}$ necessário. Pensando nisso, a seguir será disponibilizado um guia prático comentado de como fazer esses cálculos usando o software PeakMaster ${ }^{\circledR}$.

\section{Interface do software}

O PeakMaster ${ }^{\circledR}$ é um software desenvolvido para simular a separação de compostos em análises por eletroforese capilar (CE, Capillary Electrophoresis), considerando algumas condições experimentais. Dentre estas, estão as características do eletrólito utilizado, em geral, compostos por soluções tampão com ou sem ajuste de força iônica. De todas as ferramentas disponíveis no software, serão aqui apresentados os recursos que permitem o cálculo de $\mathrm{pH}$, capacidade tamponante e força iônica de soluções. O software conta com um banco de dados com a compilação de um amplo portfólio de compostos e as respectivas informações de $\mathrm{pKa}$, os quais podem ser usados para a preparação de soluções tampão.

Caso seja necessário, pode-se ainda adicionar a esse banco de dados informações de novas moléculas as quais poderão ser utilizados nos cálculos voltados para o preparo das soluções de interesse. Os comandos a serem utilizados são simples e o software apresenta uma interface amigável e intuitiva. Após a inserção dos dados necessários nos campos adequados, é possível acionar o comando para a realização dos cáculos de maneira exata, sendo as informações dos resultados de $\mathrm{pH}$, força iônica e capacidade tamponante apresentados em um template de saída, conforme apresentado na Figura 1.

\section{Inserindo dados para cálculo}

A maneira pragmática de inserir as informações necessárias para obter os dados necessários para o preparo de um determinado tampão (Figura 1) requer alguns passos, são eles:

1. Inicialmente clicar no comando " $+A d d$ " da interface principal. A janela secundária "Add BGE constituent" será aberta, conforme a Figura 2.

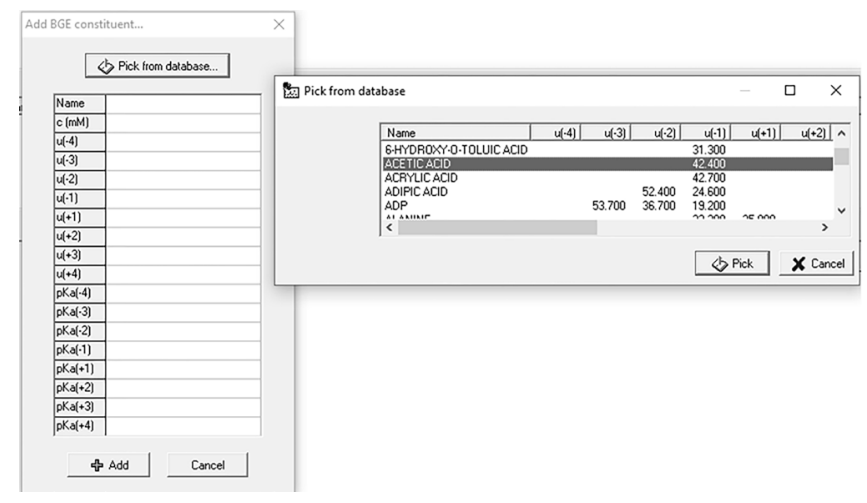

Figura 2. Interface da janela secundária "Add BGE constituent"

2. Clicar em "Pick from database", selecionar o primeiro reagente constituinte da solução tampão desejada e clicar em "Pick"

3. Adicionar a concentração desejada do reagente selecionado na lacuna " $\mathrm{C}(\mathrm{mM})$ ". Os valores de $\mathrm{pKa}$ aparecerão automaticamente na lacuna correspondente.

4. Uma vez selecionado o primeiro componente, a operação deve ser repetida até completar a composição da solução desejada.

5. A caixa "Ionic strength correction" da interface principal deve ser desmarcada.

6. Por fim, clicar no comando "Calculate".

\section{Inserindo novos compostos à base de dados do software}

Caso necessário, um novo composto pode ser adicionado ao banco de dados do PeakMaster®. Para isso, os passos requeridos são: 1. Abrir a janela "modify database" dentro do comando "Tools" da

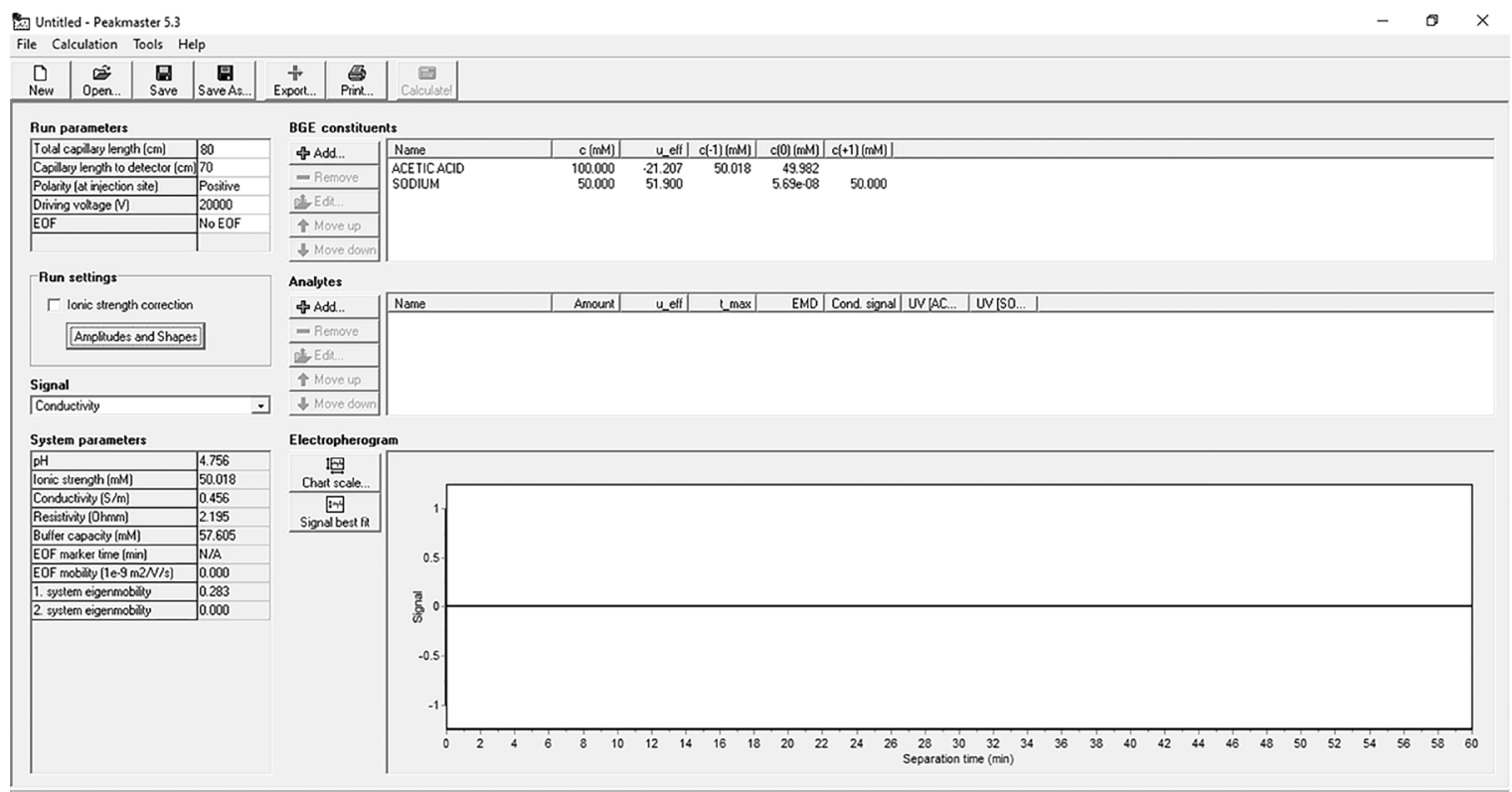

Figura 1. Interface principal do software PeakMaster ${ }^{\circledR}$ 
interface principal. Nesta, clicar em " $+A d d$ " para abrir a janela "Add constituent to database" conforme indicado na Figura 3.

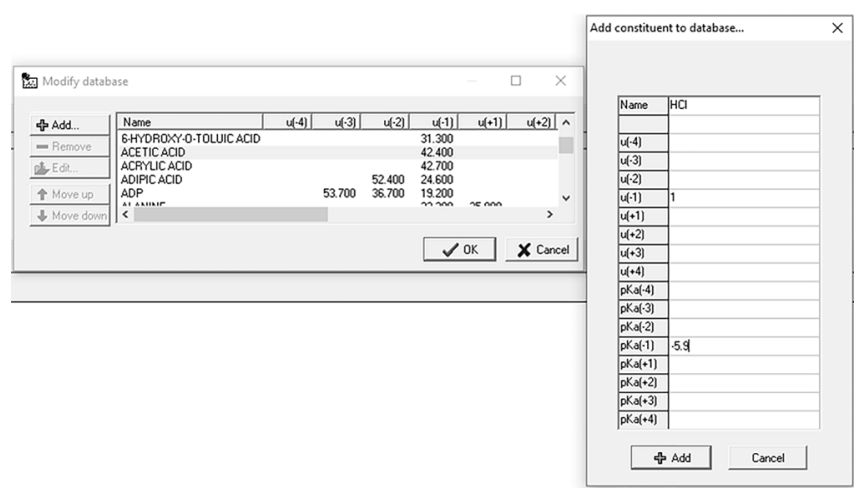

Figura 3. Interface da janela secundária "Modify database"

2. Inserir o nome do composto desejado na lacuna correspondente.

3. Inserir o pKa na lacuna correspondente. Lembrando que as lacunas são organizadas para inserção do pKa de acordo com a ordem de ionização, ou seja, "pKa(-1)" corresponde à primeira ionização, "pKa(-2)” à segunda ionização, e assim sucessivamente.

4. Conforme comentado anteriormente, o PeakMaster® é um software desenvolvido prioritariamente para simulação de experimentos a serem realizados por eletroforese capilar, logo, um dado importante para essa finalidade é a mobilidade eletroforética, indicado no software como “( $\mu)$ ”. No caso de cálculos voltados apenas para preparo de solução tampão esse dado não é relevante, porém essa lacuna deve ser preenchida para completar o processo de inserção de dados. Então, na lacuna " $\mu$ " deve ser inserido qualquer número positivo.

5. Para finalizar, clicar no comando " $+A d d$ ” seguido de " $O K$ ”. O novo componente já estará disponível.

No exemplo indicado, foram inseridos o pKa na lacuna "pKa(-1)" e um número positivo aleatório na lacuna da mobilidade " $\mu(-1)$ " para insersão do ácido clorídrico $(\mathrm{HCl})$ no banco de dados. ${ }^{26}$ Ácidos fortes como o $\mathrm{HCl}$ são completamente dissociados em água, por isso são estimados valores de $\mathrm{Ka}$ tendendo ao infinito, consequentemente, valores negativos de $\mathrm{pKa} .^{4}$

\section{Cálculo da concentração dos reagentes para o preparo de uma solução tampão}

Supondo que seja necessário preparar uma solução tampão de $\mathrm{pH}$ 6,50. Nesse caso, poderia ser escolhido o sistema dihidrogenofosfato/ hidrogenofosfato $\left(\mathrm{NaH}_{2} \mathrm{PO}_{4} / \mathrm{Na}_{2} \mathrm{HPO}_{4}\right)(\mathrm{pKa} 7,21)$. Como discutido anteriormente, quando $\mathrm{pKa} \neq \mathrm{pH}$, o tampão não está em sua máxima capacidade tamponante, porém, desde que esteja entre pKa \pm 1 ainda funciona eficientemente como um tampão. Destaca-se que a capacidade tamponante também é calculada pelo PeakMaster ${ }^{\circledR}$.

Esse sistema pode ser otimizado de diferentes formas dependendo dos reagentes disponíveis no laboratório, seja partindo do ácido fosfórico $\left(\mathrm{H}_{3} \mathrm{PO}_{4}\right)$ e de uma base forte como o hidróxido de sódio $(\mathrm{NaOH})$, ou do fosfato de sódio $\left(\mathrm{Na}_{3} \mathrm{PO}_{4}\right)$ e de um ácido forte como o ácido clorídrico $(\mathrm{HCl})$, ou diretamente da mistura dihidrogenofosfato de sódio $\left(\mathrm{NaH}_{2} \mathrm{PO}_{4}\right)$ com o hidrogenofosfato de sódio $\left(\mathrm{Na}_{2} \mathrm{HPO}_{4}\right)$ ou outro contraíon compatível.

No entanto, quais seriam as concentrações necessárias de cada um dos reagentes selecionados? Esse problema pode ser solucionado usando o PeakMaster®! De acordo com o passo-a-passo, o usuário pode inserir os reagentes disponíveis com valores de concentrações arbitrários e por método de tentativa e erro ajustar tais concentrações até atingir o pH desejado.

\section{A partir do ácido fosfórico e do hidróxido de sódio}

Por esse procedimento temos que a proporção necessária para o preparo seria de, por exemplo, $100 \mathrm{mmol} \mathrm{L}^{-1}$ de ácido fosfórico e 116,5 mmol L $\mathrm{m}^{-1}$ de uma solução de hidróxido de sódio para obtenção de um tampão $\left(\mathrm{NaH}_{2} \mathrm{PO}_{4} / \mathrm{Na}_{2} \mathrm{HPO}_{4}\right)$ com concentração total de 100 mmol L ${ }^{-1}$ e $\mathrm{pH} 6,5$, de acordo com os resultados calculados pelo PeakMaster $^{\circledR}$, conforme apresentado na Figura 4.

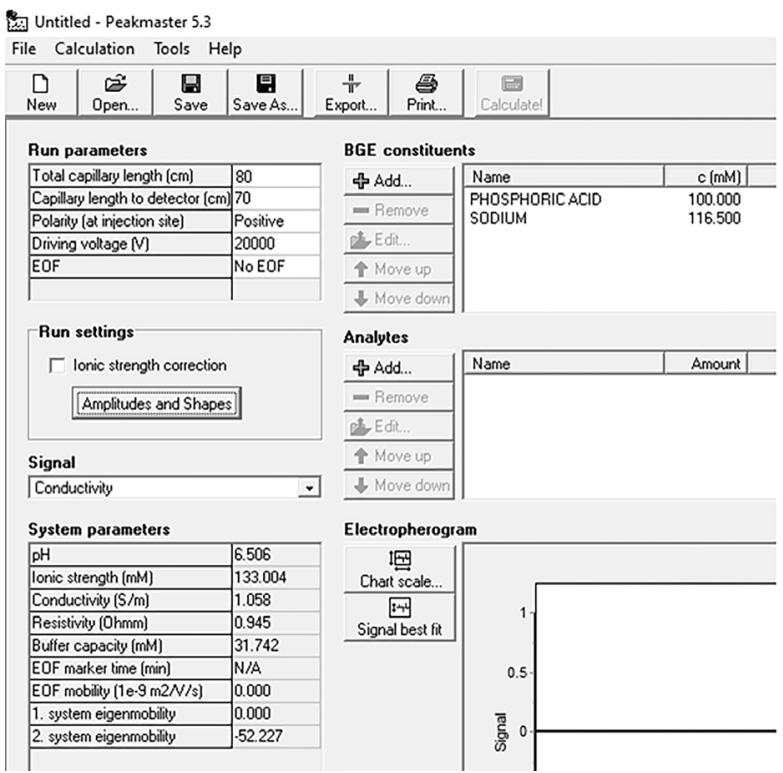

Figura 4. Interface principal do software PeakMaster ${ }^{\circledR}$ após inserção de dados para cálculo de pH do tampão $\left(\mathrm{NaH}_{2} \mathrm{PO}_{4} / \mathrm{Na}_{2} \mathrm{HPO}_{4}\right)$ usando $\mathrm{H}_{3} \mathrm{PO}_{4}$ e $\mathrm{NaOH}$

Vale lembrar que, neste exemplo o tampão foi estabelecido após o deslocamento de equilíbrio do ácido fosfórico até o equilibrio correspondente ao tampão em questão, conforme o esquema:

\begin{tabular}{lccc}
\multicolumn{5}{c}{$\mathrm{H}_{3} \mathrm{PO}_{4}(\mathrm{aq})+\mathrm{OH}^{-}(\mathrm{aq}) \rightleftharpoons \mathrm{H}_{2} \mathrm{PO}_{4}^{-}(\mathrm{aq})+\mathrm{H}_{2} \mathrm{O}(\mathrm{l}) \mathrm{pKa}=2,15$} \\
$\mathrm{t}_{0}$ & $100 \mathrm{mmol} \mathrm{L}^{-1}$ & $116,5 \mathrm{mmol} \mathrm{L}^{-1}$ & - \\
$\mathrm{t}_{\mathrm{eq}}$ & $-100 \mathrm{mmol} \mathrm{L}^{-1}$ & $-100 \mathrm{mmol} \mathrm{L}^{-1}$ & $100 \mathrm{mmol} \mathrm{L}^{-1}$ \\
$\mathrm{t}_{\mathrm{f}}$ & 0 & $16,5 \mathrm{mmol} \mathrm{L}^{-1}$ & $100 \mathrm{mmol} \mathrm{L}^{-1}$ \\
\multicolumn{5}{c}{} & $\mathrm{H}_{2} \mathrm{PO}_{4}^{-}(\mathrm{aq})+\mathrm{OH}^{-}(\mathrm{aq}) \rightleftharpoons \mathrm{HPO}_{4}^{2-}(\mathrm{aq})+\mathrm{H}_{2} \mathrm{O}(\mathrm{l}) \quad \mathrm{pKa}=7,21$ \\
$\mathrm{t}_{0}$ & $100 \mathrm{mmol} \mathrm{L}^{-1}$ & $16,5 \mathrm{mmol} \mathrm{L}$ & - \\
$\mathrm{t}_{\mathrm{eq}}$ & $-16,5 \mathrm{mmol} \mathrm{L}^{-1}$ & $-16,5 \mathrm{mmol} \mathrm{L}^{-1}$ & $16,5 \mathrm{mmol} \mathrm{L}^{-1}$ \\
$\mathrm{t}_{\mathrm{f}}$ & $83,5 \mathrm{mmol} \mathrm{L}^{-1}$ & 0 & $16,5 \mathrm{mmol} \mathrm{L}^{-1}$
\end{tabular}

No exemplo, a concentração total da solução tampão é de 100 mmol L-1, conforme os cálculos da expressão 19:

$$
\begin{aligned}
\mathrm{C}_{\text {Total }}=\mathrm{C}_{\text {ácido }}+\mathrm{C}_{\text {base conjugada }} & =83,5 \mathrm{mmol} \mathrm{L}^{-1}+16,5 \mathrm{mmol} \mathrm{L}^{-1}= \\
& =100 \mathrm{mmol} \mathrm{L}^{-1}
\end{aligned}
$$

Caso seja necessário preparar uma solução com concentração total menor ou maior, basta ajustar os valores da concentração de cada um dos reagentes, desde que seja mantido a mesma proporção. Esses cálculos também podem ser realizados e/ou conferidos inserindo os novos valores de concentração no PeakMaster ${ }^{\circledR}$ e acompanhando a resposta gerada.

A partir dos dihidrogenofosfato e hidrogenofosfato de sódio

Por esse procedimento, temos que a proporção necessária para o 
preparo seria de, por exemplo, uma massa de dihidrogenofosfato de sódio correspondente a um solução $100 \mathrm{mmol} \mathrm{L}^{-1} \mathrm{e}$ de uma massa de hidrogenofosfato de sódio correspondente a uma solução $25 \mathrm{mmol} \mathrm{L}^{-1}$ para obtenção de um tampão $\left(\mathrm{NaH}_{2} \mathrm{PO}_{4} / \mathrm{Na}_{2} \mathrm{HPO}_{4}\right)$ com concentração total de $125 \mathrm{mmol} \mathrm{L}^{-1}$ epH 6,5, de acordo com os resultados calculados pelo PeakMaster ${ }^{\circledR}$, conforme apresentado na Figura 5.

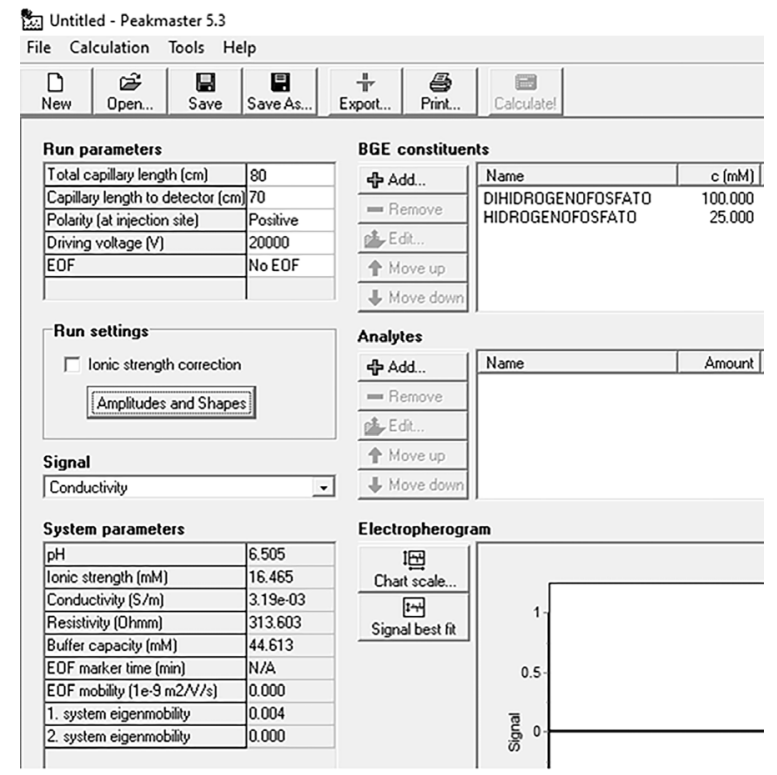

Figura 5. Interface principal do software PeakMaster ${ }^{\circledR}$ após inserção de dados para cálculo de pH do tampão $\left(\mathrm{NaH}_{2} \mathrm{PO}_{4} / \mathrm{Na}_{2} \mathrm{HPO}_{4}\right)$ usando $\mathrm{NaH}_{2} \mathrm{PO}_{4}$ e $\mathrm{Na}_{2} \mathrm{HPO}_{4}$

Nesse exemplo, após dissociação dos sais em meio aquoso, o tampão é estabelecido diretamente pelo equilíbrio correspondente ao mesmo, conforme o esquema:

$$
\begin{aligned}
& \mathrm{H}_{2} \mathrm{PO}_{4}^{-}(\mathrm{aq})+\mathrm{H}_{2} \mathrm{O}(\mathrm{l}) \rightleftharpoons \mathrm{HPO}_{4}^{2-}(\mathrm{aq})+\mathrm{H}_{3} \mathrm{O}^{+}(\mathrm{aq}) \quad \mathrm{pKa}=7,21 \\
& 100 \mathrm{mmol} \mathrm{L}^{-1} \quad 25 \mathrm{mmol} \mathrm{L}^{-1}
\end{aligned}
$$

No exemplo, a concentração total da solução tampão é de $125 \mathrm{mmol} \mathrm{L}^{-1}$, conforme os cálculos da expressão 20:

$$
\begin{aligned}
\mathrm{C}_{\text {Total }}=\mathrm{C}_{\text {ácido }}+\mathrm{C}_{\text {base conjugada }} & =100 \mathrm{mmol} \mathrm{L}^{-1}+25 \mathrm{mmol} \mathrm{L}^{-1} \\
& =125 \mathrm{mmol} \mathrm{L}^{-1}
\end{aligned}
$$

Vale lembrar que, para ser possível o cálculo dessa solução partindo desses reagentes usando o PeakMaster ${ }^{\circledR}$, informações dos mesmos devem ser adicionados ao banco de dados do software. No entanto, nesse caso algumas considerações devem ser feitas.

Primeiramente, devemos inserir na plataforma informações das espécies ácidas e/ou básicas que resultam da dissociação dos sais em questão e seus respectivos valores de $\mathrm{pKa}$ e/ou pKb. Destaca-se que assim deve ser feito sempre que o composto de interesse para o cálculo é um sal. Lembre-se ainda que nesse caso a intenção é controlar as concentrações de compostos em diferentes direções de um mesmo equilíbrio, sendo o dihidrogenofosfato a espécie ácida e o hidrogenofostafo sua base conjugada. Sendo assim, devemos inserir os compostos separamente de acordo com seu comportamento em solução para que cálculo seja correto. Dessa forma:

$$
\begin{aligned}
& \mathrm{H}_{2} \mathrm{PO}_{4}^{-}(\mathrm{aq})+\mathrm{H}_{2} \mathrm{O}(\mathrm{l}) \rightleftharpoons \mathrm{HPO}_{4}^{2-}(\mathrm{aq})+\mathrm{H}_{3} \mathrm{O}^{+}(\mathrm{aq}) \quad \mathrm{pKa}=7,21 \text { (ácido) } \\
& \mathrm{HPO}_{4}^{2-}(\mathrm{aq})+\mathrm{H}_{2} \mathrm{O}(\mathrm{l}) \rightleftharpoons \mathrm{H}_{2} \mathrm{PO}_{4}^{-}(\mathrm{aq})+\mathrm{OH}^{-}(\mathrm{aq}) \quad \mathrm{pKb}=14-7,21
\end{aligned}
$$$$
=6,79 \text { (base conjugada) }
$$

Para isso, basta adicionar ao software as informações pertinentes do ácido, inserindo o valor de pKa na lacuna " $p K a(-1)$ ”, bem como as informações da base conjugada, inserindo o valor de $\mathrm{pKa}$ na lacuna “pKa $(+1)$ ”, de acordo com o procedimento de modificação de banco de dados descrito anteriormente. Assim, os dois compostos principais do tampão em questão estarão disponíveis para serem usados nos cálculos. A dedução entre a relação de $\mathrm{pKa}$ e pKb está detalhada no Material Suplementar.

\section{A partir do fosfato de sódio e do ácido clorídrico}

Por esse procedimento temos que a proporção necessária para o preparo seria de, por exemplo, uma massa de fosfato de sódio correspondente a uma solução de $100 \mathrm{mmol} \mathrm{L}^{-1}$ e $116,5 \mathrm{mmol} \mathrm{L}^{-1}$ de uma solução de ácido clorídrico para obtenção de um tampão $\left(\mathrm{NaH}_{2} \mathrm{PO}_{4} / \mathrm{Na}_{2} \mathrm{HPO}_{4}\right)$ com concentração total de $100 \mathrm{mmol} \mathrm{L}^{-1} \mathrm{e}$ pH 6,5, de acordo com os resultados calculados pelo PeakMaster ${ }^{\circledR}$, conforme apresentado na Figura 6.

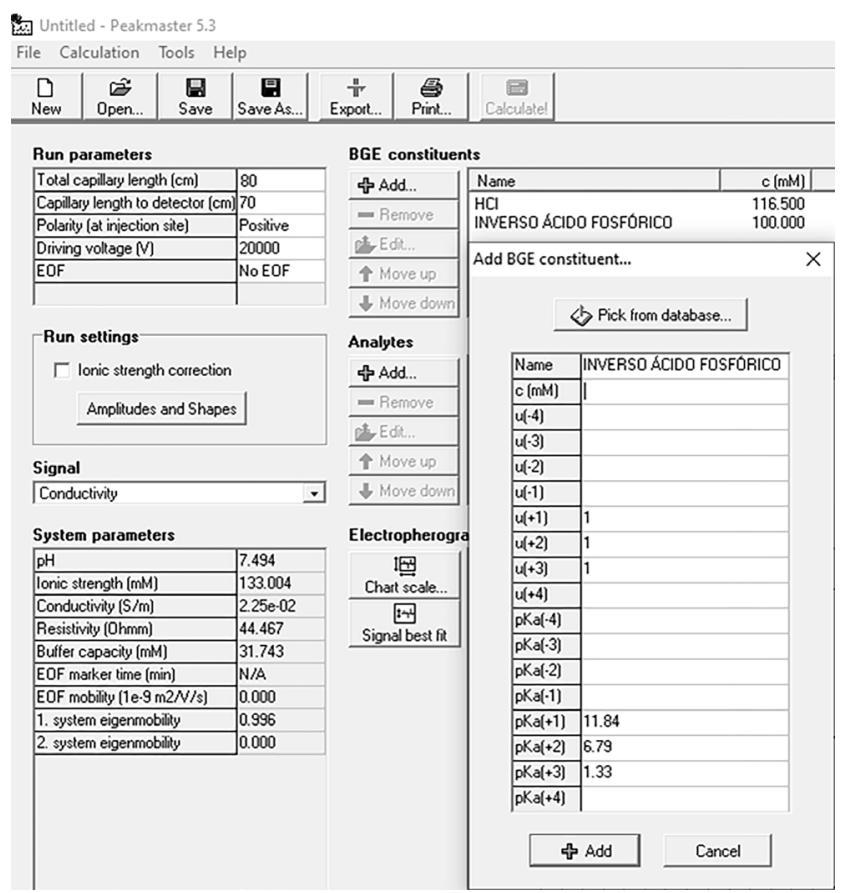

Figura 6. Interface principal do software PeakMaster ${ }^{\circledR}$ após inserção de dados para cálculo de $\mathrm{pH}$ do tampão $\left(\mathrm{NaH}_{2} \mathrm{PO}_{4} / \mathrm{Na}_{2} \mathrm{HPO}_{4}\right)$ usando $\mathrm{Na}_{3} \mathrm{PO}_{4}$ e $\mathrm{HCl}$

Observe que no exemplo o tampão foi estabelecido após o deslocamento do equilíbrio do fosfato de sódio até o equilíbrio correspondente ao tampão em questão, ou seja, adotamos o procedimento inverso do primeiro exemplo supracitado. Aqui, partimos das bases conjugadas e adicionamos um ácido forte para deslocamento de equilíbrio, conforme o esquema:

$$
\mathrm{PO}_{4}^{3-}(\mathrm{aq})+\mathrm{H}_{3} \mathrm{O}(\mathrm{aq}) \rightleftharpoons \mathrm{HPO}_{4}^{2-}(\mathrm{aq})+\mathrm{H}_{2} \mathrm{O}(\mathrm{l}) \quad \mathrm{pKb}=1,33
$$

$\mathrm{t}_{0} \quad 100 \mathrm{mmol} \mathrm{L}^{-1} \quad 116,5 \mathrm{mmol} \mathrm{L}^{-1}$

$\mathrm{t}_{\mathrm{eq}} \quad-100 \mathrm{mmol} \mathrm{L}^{-1}-100 \mathrm{mmol} \mathrm{L}^{-1} \quad 100 \mathrm{mmol} \mathrm{L}^{-1}$

$\mathrm{t}_{\mathrm{f}} \quad 0 \quad 16,5 \mathrm{mmol} \mathrm{L}^{-1} \quad 100 \mathrm{mmol} \mathrm{L}^{-1}$

$$
\mathrm{HPO}_{4}^{2-}(\mathrm{aq})+\mathrm{H}_{3} \mathrm{O}(\mathrm{aq}) \rightleftharpoons \mathrm{H}_{2} \mathrm{PO}_{4}^{-}(\mathrm{aq})+\mathrm{H}_{2} \mathrm{O}(\mathrm{l}) \quad \mathrm{pKb}=6,79
$$

$\mathrm{t}_{0} \quad 100 \mathrm{mmol} \mathrm{L}^{-1} \quad 16,5 \mathrm{mmol} \mathrm{L}^{-1} \quad-$

$\mathrm{t}_{\text {eq }} \quad-16,5 \mathrm{mmol} \mathrm{L}^{-1}-16,5 \mathrm{mmol} \mathrm{L}^{-1} \quad 16,5 \mathrm{mmol} \mathrm{L}^{-1}$

$\mathrm{t}_{\mathrm{f}} \quad 83,5 \mathrm{mmol} \mathrm{L}^{-1} \quad 0 \quad 16,5 \mathrm{mmol} \mathrm{L}^{-1}$

No exemplo, a concentração total da solução tampão é de $100 \mathrm{mmol} \mathrm{L}^{-1}$, conforme o cálculo da expressão 21 : 
$\mathrm{C}_{\text {Total }}=\mathrm{C}_{\text {base }}+\mathrm{C}_{\text {ácido conjugado }}=83,5 \mathrm{mmol} \mathrm{L}^{-1}+16,5 \mathrm{mmol} \mathrm{L}^{-1}$ $=100 \mathrm{mmol} \mathrm{L}^{-1}$

Destaca-se que uma vez que estamos trabalhando com as reações inversas, ou seja, a partir das bases conjugadas, os valores de pKa também devem ser convertidos em valores de $\mathrm{pKb}$ para inserção no banco de dados, conforme indicado também na Figura 6. Consequentemente, nesse caso estamos monitorando o pOH, logo, ao preencher as lacunas de concentração de reagente e prosseguir com o procedimento por tentativa e erro, deve-se buscar pelo valor do $\mathrm{pOH}$, conforme a expressão 22 :

$$
14-\mathrm{pH} \text { desejado }=14-6,5=7,5
$$

A dedução entre a relação de $\mathrm{pKa}$ e $\mathrm{pKb}$ e $\mathrm{pH}$ e pOH está detalhada no Material Suplementar.

Por fim, uma vez estabelecido os reagentes e as concentrações de cada um destes, basta calcular os volumes e massas necessários para o preparo do tampão.

\section{Cálculo do ajuste de força iônica de uma solução tampão}

Agora, vamos supor que seja necessário preparar uma solução tampão (Tris(hidroximetil)amino metano/ $\mathrm{HCl}$ ), ou resumidamente (Tris/HCl), de pH 8,0 com força iônica de $100 \mathrm{mmol} \mathrm{L}^{-1}$. Fazendo os cálculos pelo PeakMaster® temos que para o preparo dessa solução podemos adicionar uma massa de Tris para o preparo de uma solução $100 \mathrm{mmol} \mathrm{L}^{-1}$ e um volume de $\mathrm{HCl}$ para o preparo de uma solução $50 \mathrm{mmol} \mathrm{L}^{-1}$, conforme apresentado na Figura 7.

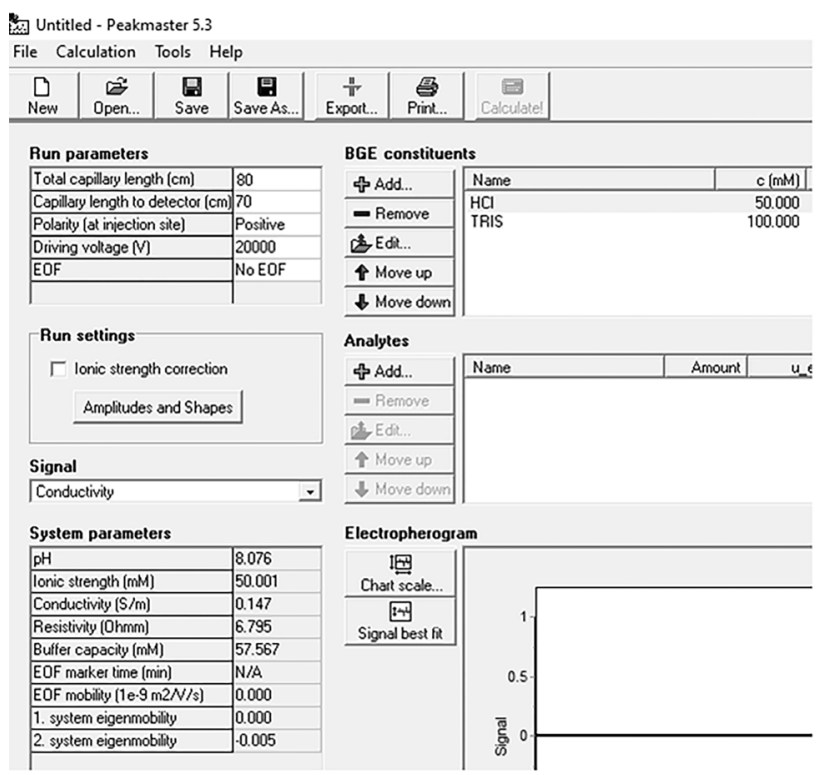

Figura 7. Interface principal do software PeakMaster ${ }^{\circledast}$ após inserção de dados para cálculo de pH e força ionica do tampão $(\mathrm{Tris} / \mathrm{HCl})$

Desse modo, obtemos uma solução com força iônica de $50 \mathrm{mmol} \mathrm{L}^{-1}$, conforme calculado pelo software. Para atingirmos a força iônica desejada, temos duas opções:

(a) Ajustar a concentração dos reagentes mantendo a proporção. Por exemplo, ao dobrarmos as concentrações, adicionando uma massa de Tris para o preparo de uma solução $200 \mathrm{mmol} \mathrm{L}^{-1} \mathrm{e}$ um volume de $\mathrm{HCl}$ para o preparo de uma solução $100 \mathrm{mmol} \mathrm{L}^{-1}$, obtemos uma nova solução tampão com concentração total de $200 \mathrm{mmol}$ $\mathrm{L}^{-1}$ e força iônica de $100 \mathrm{mmol} \mathrm{L}^{-1}$, como indicado na Figura 8.

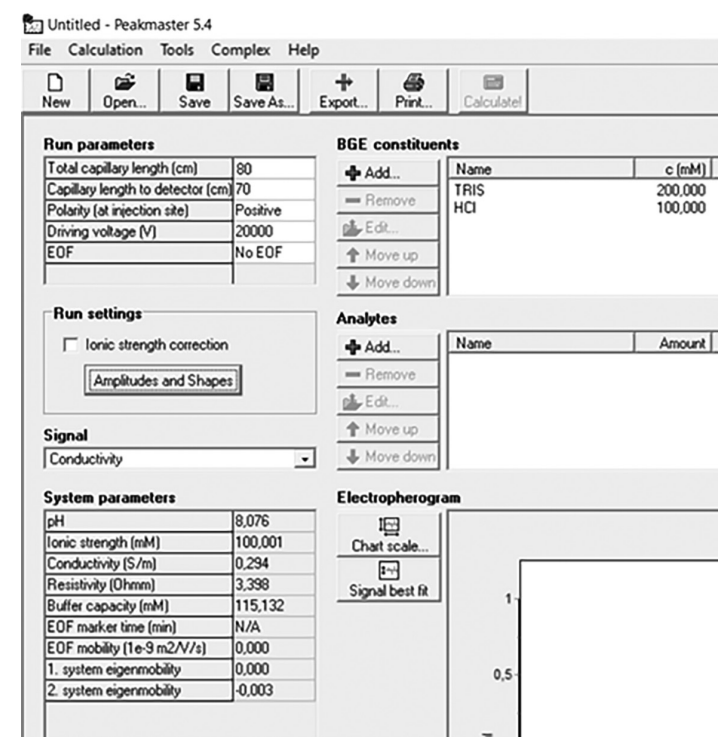

Figura 8. Interface principal do software PeakMaster ${ }^{\circledR}$ após inserção de dados para cálculo de força iônica do tampão (Tris/HCl) com ajuste de concentração

(b) Adicionar uma massa de $\mathrm{M}^{+} \mathrm{A}^{\text {; }}$, por exemplo, para completar a concentração de íons em solução. Nesse caso basta subtrair o valor da força iônica desejado do valor atual. Desse modo, deve ser adicionado uma massa de $\mathrm{KCl}$ necessária para o preparo de uma solução $50 \mathrm{mmol} \mathrm{L}^{-1} \mathrm{e}$ obteremos um tampão Tris/HCL com concentração total de $100 \mathrm{mmol} \mathrm{L}^{-1}$ e força iônica de $100 \mathrm{mmol} \mathrm{L}^{-1}$. Esse cálculo também pode ser realizado e/ou conferido usando o PeakMaster®, conforme apresentado na Figura 9.

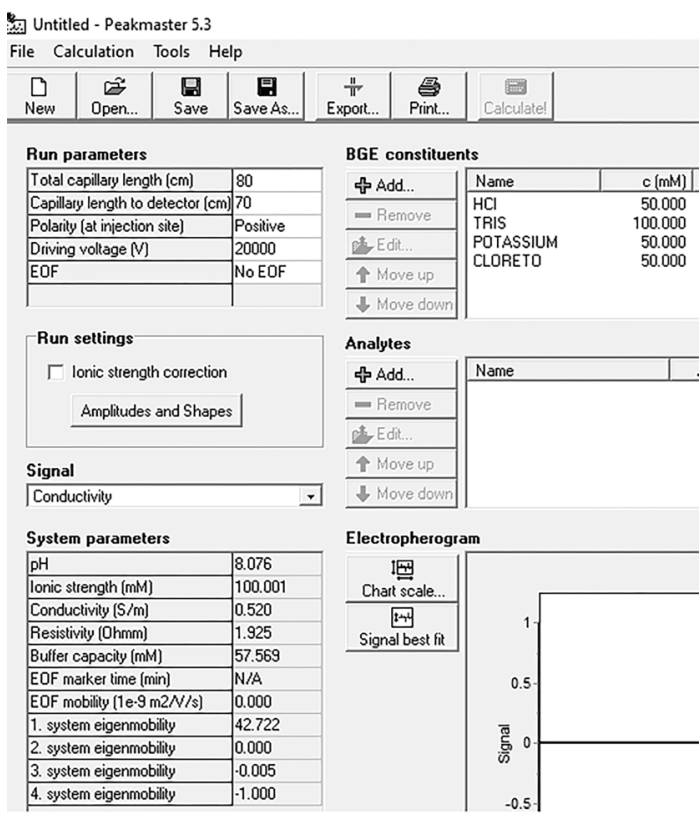

Figura 9. Interface principal do software PeakMaster ${ }^{\boxplus}$ após inserção de dados para cálculo de força iônica do tampão (Tris/HCl) ajustado com $\mathrm{KCl}$

Vale lembrar que nesse exemplo temos um tampão preparado a partir de uma base fraca (TRIS) e seu ácido conjugado (TRISH ${ }^{+}$), cujo equilíbrio é atingido em virtude da adição de um ácido forte, aqui exemplificado com o $\mathrm{HCl}$, conforme a expressão do equilíbrio 23 :

$$
\operatorname{TRIS}(\mathrm{aq})+\mathrm{HCl}(\mathrm{aq}) \rightleftharpoons \mathrm{TRISH}^{+} \mathrm{Cl}^{-}(\mathrm{aq})+\mathrm{H}_{2} \mathrm{O}(\mathrm{l})
$$

Uma vez calculadas as concentrações, basta calcular as 
respectivas massas e volumes dos reagentes, conforme comentado nos exemplos anteriores.

\section{Esquema simplificado}

De modo geral, acreditamos que os exemplos supracitados sejam suficientes para o usuário adquirir domínio no uso do software, bem como, entender os cálculos e adquirir o know how necesário para mediar o preparo de uma solução tampão, com ou sem controle da força iônica. Em resumo, as etapas dos cálculos e demais considerações a serem realizadas durante o procedimento completo de preparo de uma solução tampão estão detalhadas no fluxograma da Figura 10.

Na Tabela 1 são listados alguns outros exemplos de tampões tradicionais e seus respectivos valores recomendados de concentração para o preparo a partir do ácido fraco principal e hidróxido de

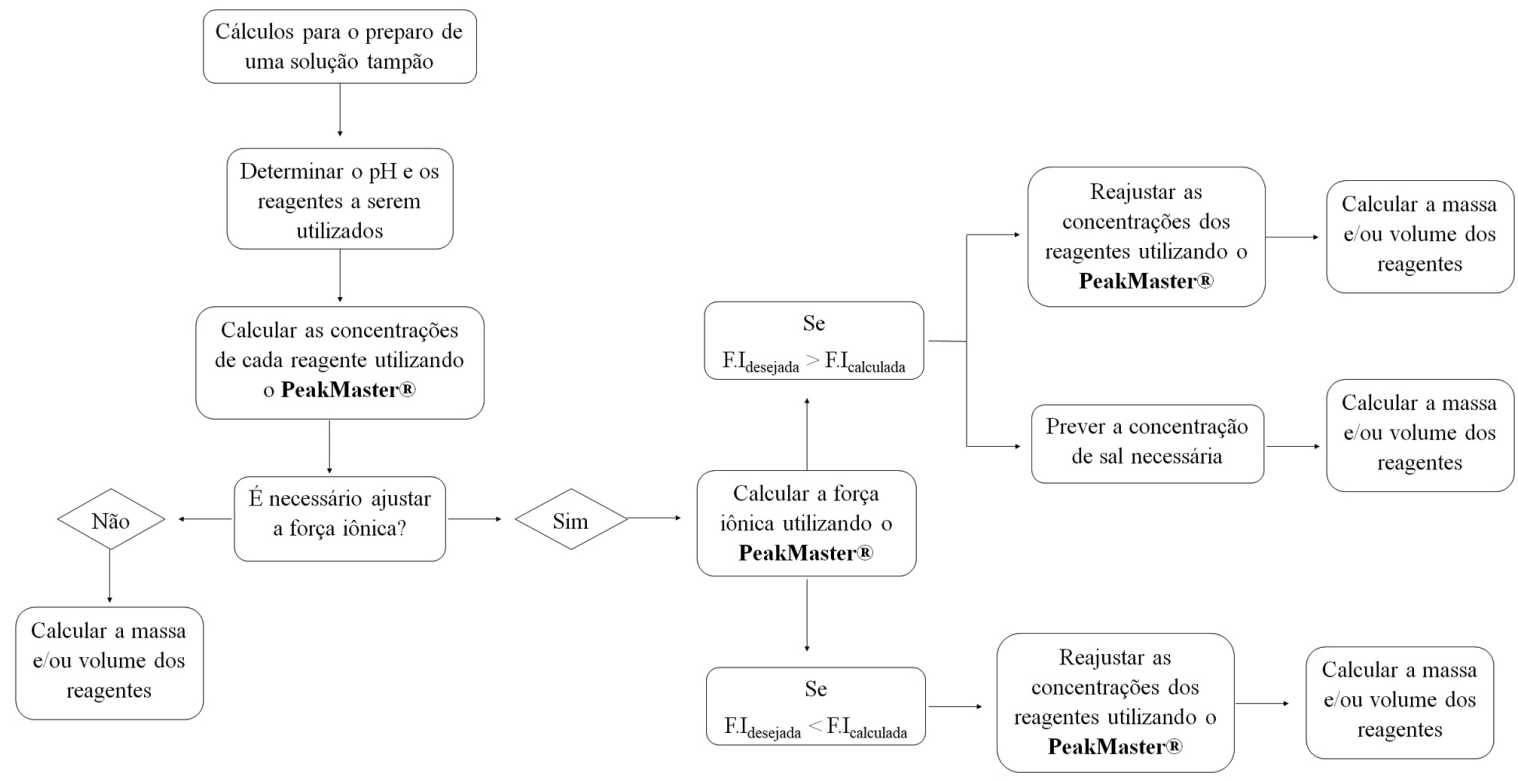

Figura 10. Fluxograma das etapas de cálculos envolvidos no preparo de uma solução tampão

Tabela 1. Dados de alguns tampões tradicionais e seus respectivos valores recomendados de concentração para o preparo a partir do ácido fraco principal e hidróxido de sódio (ou qualquer contraíon compatível), calculados usando o PeakMaster ${ }^{\circledR}$

\begin{tabular}{|c|c|c|c|c|c|c|c|c|}
\hline \multirow{2}{*}{$\begin{array}{l}\text { pH desejado } \\
\text { a } 25^{\circ} \mathrm{C}\end{array}$} & \multirow{2}{*}{ Tampão } & \multirow{2}{*}{$\mathrm{pKa}^{4,22}$} & \multicolumn{2}{|c|}{$\begin{array}{l}\text { Concentração dos reagentes } \\
\left(\mathrm{mmol} \mathrm{L}^{-1}\right)\end{array}$} & \multirow{2}{*}{$\begin{array}{l}\text { Força iônica } \\
\left(\mathrm{mmol} \mathrm{L} \mathrm{L}^{-1}\right)\end{array}$} & \multirow{2}{*}{$\begin{array}{l}\text { Capacidade } \\
\text { tamponante } \\
\left(\mathrm{mmol} \mathrm{L}^{-1}\right)\end{array}$} & \multicolumn{2}{|c|}{$\begin{array}{c}\text { Massa de } \mathrm{KCl}(\mathrm{g}) \text { por litro de solução } \\
\text { para atingir a força iônica de: }\end{array}$} \\
\hline & & & $\mathrm{C}_{\text {ácido }}$ & $\mathrm{C}_{\mathrm{NaOH}}$ & & & $0,5 \mathrm{~mol} \mathrm{~L}^{-1}$ & $1,0 \mathrm{~mol} \mathrm{~L}^{-1}$ \\
\hline 3,8 & $\begin{array}{l}\text { (Ácido acético/ } \\
\text { Acetato) }\end{array}$ & 4,8 & 100 & 9 & 9 & 20 & 36,6 & 73,9 \\
\hline 4,8 & & & 100 & 50 & 50 & 58 & 33,3 & 70,8 \\
\hline 5,8 & & & 100 & 91 & 91 & 18 & 30,5 & 67,8 \\
\hline 8,2 & $\begin{array}{l}\text { (Ácido bórico/ } \\
\text { Borato) }\end{array}$ & 9,2 & 100 & 9 & 9 & 19 & 36,6 & 73,9 \\
\hline 9,2 & & & 100 & 50 & 50 & 58 & 33,3 & 70,8 \\
\hline 10,2 & & & 100 & 91 & 91 & 20 & 30,5 & 67,8 \\
\hline 11,8 & & 12,8 & 100 & 115 & 123 & 35 & 28,1 & 65,4 \\
\hline 12,8 & & & 100 & 227 & 254 & 230 & 18,3 & 55,6 \\
\hline 3,1 & $\begin{array}{l}\text { (Ácido cítrico/ } \\
\text { Citrato) }\end{array}$ & 3,1 & 100 & 50 & 52 & 64 & 33,4 & 70,7 \\
\hline 4,8 & & 4,8 & 100 & 150 & 202 & 68 & 22,2 & 59,5 \\
\hline 6,4 & & 6,4 & 100 & 250 & 451 & 62 & 3,65 & 40,9 \\
\hline 6,3 & $\begin{array}{l}\text { (Ácido carbônico/ } \\
\text { Carbonato) }\end{array}$ & 6,3 & 100 & 50 & 50 & 58 & 33,3 & 70,8 \\
\hline 10,3 & & 10,3 & 100 & 150 & 200 & 58 & 22,4 & 59,6 \\
\hline 2,2 & $\begin{array}{l}\text { (Ácido fosfórico / } \\
\text { Fosfato) }\end{array}$ & 2,2 & 100 & 50 & 50 & 74 & 33,5 & 70,8 \\
\hline 3,2 & & & 100 & 90 & 90 & 21 & 30,5 & 67,8 \\
\hline 6,2 & & 7,21 & 100 & 110 & 120 & 21 & 28,3 & 65,5 \\
\hline 7,2 & & & 100 & 150 & 200 & 58 & 22,4 & 59,6 \\
\hline 8,2 & & & 100 & 190 & 280 & 21 & 16,4 & 53,6 \\
\hline 11,7 & & 12,7 & 100 & 220 & 340 & 43 & 11,9 & 49,2 \\
\hline 12,7 & & & 100 & 320 & 492 & 216 & 0,59 & 37,9 \\
\hline
\end{tabular}


sódio (ou qualquer contraíon compatível), calculados usando o PeakMaster®. São apresentados, ainda, os valores de força iônica, capacidade tamponante, além da massa de $\mathrm{KCl}$ a ser adicionada para ajuste de força iônica nos valores de $0,5 \mathrm{~mol} \mathrm{~L}^{-1}$ e $1 \mathrm{~mol} \mathrm{~L}^{-1}$.

\section{PREPARO DA SOLUÇÃO}

Após obtenção dos valores de concentração, bem como das massas e volumes de reagentes necessários, a próxima etapa envolve o preparo da solução propriamente dita. Primeiramente, é importante ressaltar que o usuário deve planejar corretamente, revisar o procedimento e o seguir cuidadosamente. Além de utilizar vidrarias e demais instrumentos adequados, equipamentos de proteção individual (EPIs) e proceder com atenção e cautela, a fim de garantir que o procedimento seja realizado com segurança. ${ }^{27} \mathrm{Em}$ seguida, as massas previstas dos reagentes sólidos devem ser pesadas corretamente em uma balança analítica e os volumes devem ser transferidos através de uma pipeta volumétrica ou automática devidamente calibrada. Lembre-se que, para evitar acidentes, os ácidos devem ser adicionados à água ou às bases, e não o contrário. Uma vez solubilizados e adicionados todos os reagentes a um balão volumétrico adequado, deve-se verificar o $\mathrm{pH}$ e por fim completar o volume com água deionizada. Recomenda-se a verificação do $\mathrm{pH}$ da solução recém preparada em $\mathrm{pHmetro}$ contendo eletrodos para soluções aquosas, de acordo as especificações de utilização e manutenção descritas pelo fabricante.

Note que pode haver sutis diferenças entre o valor de $\mathrm{pH}$ registrado no potenciometro e o almejado, devido às incertezas associadas principalmente às constantes de equilíbrio, à temperatura do ambiente e aos reagentes voláteis, higroscópios e de pureza desconhecida. Lembre-se, ainda, que medidas potenciométricas de soluções muito ácidas ( $\mathrm{pH}$ em torno de 1) bem como soluções muito alcalinas (pH em torno de 13) também têm um erro associado, visto que nessas concentrações os sítios da superfície da membrana externa do eletrodo estão saturados (com íons $\mathrm{H}^{+}$ou outro cátion monovalente, como o $\mathrm{Na}^{+}$no caso de soluções altamente alcalinas), consequentemente, nesses casos não é possível fazer uma medição precisa do $\mathrm{pH} .{ }^{3,4}$ Uma vez verificado adequadamente o $\mathrm{pH}$ da solução, se necessário, o usuário pode ajustá-lo pela adição de alíquotas de soluções concentradas de ácidos ou bases fortes. ${ }^{3}$

\section{CONCLUSÕES}

Neste trabalho foram disponibilizados alguns guias de como calcular os parâmetros necessários para o preparo de uma solução tampão com ou sem ajuste da força iônica. Através do software PeakMaster®, apresentado neste trabalho, o usuário será capaz de fazer cálculos diversos relacionados ao $\mathrm{pH}$, força iônica, capacidade tamponante e concentrações de reagentes de soluções tampão. Esperase que esse material seja uma fonte de conhecimento e esclarecimento de dúvidas para estudantes e demais pessoas com interesse no tema.

\section{MATERIAL SUPLEMENTAR}

As deduções da equação de Henderson-Hasselbach e das relações entre $\mathrm{pKa}, \mathrm{pKb}, \mathrm{pH}$ e $\mathrm{pOH}$ e o exemplo guiado do ajuste de força iônica com sal de cátion divalente, comentados anteriormente neste trabalho, estão disponíveis em http://quimicanova.sbq.org.br, na forma de arquivo PDF, com acesso livre.

\section{AGRADECIMENTOS}

Os autores agradecem à Coordenação de Aperfeiçoamento de Pessoal de Nível Superior (CAPES), ao Conselho Nacional de Desenvolvimento Científico e Tecnológico - CNPq (Projetos 303355/2017-4 e 424032/2018-0), ao Instituto Nacional de Ciência e Tecnologia de Bioanalítica - INCTBio (Projetos FAPESP 2014/50867-3 e CNPq 465,389/2014-7), à Financiadora de Inovação e Pesquisa - FINEP (Project CT-INFRA 01/2013-REF 0633/13) e à Rede Mineira de Química - RQ-MG (Projeto CEX.RED- 00010-14). Primeiro autor - Bolsista do CNPq Brasil (Processo 142502/2020-0).

\section{REFERÊNCIAS}

1. Nelson, D. L.; Cox, M. M.; Princípios de bioquímica de Lehninger, $6^{\mathrm{a}}$ ed., Artmed: Porto Alegre, 2014.

2. Atkins, P.; Jones, L.; Princípios de química: Questionando a vida moderna e meio ambiente, $5^{\mathrm{a}}$ ed., Bookman: Porto Alegre, 2012.

3. Skoog, D. A.; West, D.; Holler, J. E.; Crouch, S. R.; Fundamentos de química analítica. Tradução da $8^{a}$ edição Norte americana, Thomson: São Paulo, 2005.

4. Harris, D. C.; Quantitative Chemical Analysis, $8^{\text {th }}$ ed., WH Freeman and Company: New York, 2010.

5. Fiorucii, A. R.; Soares, M. H. F. B.; Cavalheiro, E. T. G.; Quim. Nova Esc. 2001, 13, 18.

6. Johnson, J. L. H.; Yalkowsky, S. H.; AAPS PharmSciTech 2007, 7, 2.

7. Elving, P, J.; Markowitz, J. M.; Rosenthal, I.; Anal. Chem. 1956, 28 , 1179.

8. Ellis, K. J.; Morrison, J. F.; Methods Enzymol. 1982, 87, 405.

9. Seymour, M. D.; Fernando, Q.; J. Chem. Educ. 1977, 54, 225.

10. Lambert, W. J.; J. Chem. Educ. 1990, 67, 150.

11. Richter, D. D.; Comer, P. J.; King, K. S.; Sawin, H. S.; Wright, D. S.; Soil Sci. Soc. Am. J. 1988, 52, 261.

12. Liu, J.; Wan, L.; Zhang, L.; Zhou, Q.; J. Colloid Interface Sci. 2011, $364,490$.

13. Parkes, M.; Myant, C.; Cann, P. M.; Wong, J. S. S.; Tribol. Int. 2014, 72, 108.

14. Möller, J.; Schroer, M. A.; Erlkamp, M.; Grobelny, S.; Paulus, M.; Tiemeyr, S.; Wirkert, F. J.; Tolan, M.; Winter, R.; Biophys. J. 2012, 102, 2641.

15. Norby, J. G.; Esmann, M.; J. Gen. Physiol. 1997, 109, 555.

16. Jones, K. L.; O'melia, C. R.; J. Membr. Sci. 2000, 165, 31.

17. Willey, J. D.; J. Chem. Educ. 2004, 81, 1644.

18. Carvajal, M. T.; Yalkowsky, S.; AAPS PharmSciTech 2019, 124, 1.

19. Sabadini, E.; Carvalho, L. V. C.; Quim. Nova 2013, 36, 187.

20. Caldwel, B.; Rohlman, C.; Benore-parsons, M.; Biochem. Mol. Biol. Educ. 2004, 32, 11.

21. Orgill, M.; Sutherland, A.; Chem. Educ. Res. Pract. 2008, 9, 131.

22. Gas, B.; PeakMaster; Charles University, Czech Republic, 2011.

23. Gas, B.; Jaros, M.; Hruska, V.; Zuskova, I.; Sterdy, M.; CE Currents 2005, 18, 282.

24. Harvey, D.; Modern Analytical Chemistry, $1^{\text {st }}$ ed., The Mc-Graw Hill Companies: USA, 2000.

25. Silva, C. R.; Simoni, J. A.; Quim. Nova 2000, 23, 405.

26. Trummal, A.; Lipping, L.; Kaljurand, I.; Koppel, I. A.; Leito, I.; J. Phys. Chem. A 2016, 120, 3663.

27. Brasil. Ministério da Ciência e Tecnologia; Protocolo de segurança de aerossóis, soluções aquosas e tecnologias - Laquatec, INPE: São José dos Campos, 2011. 